\title{
Electron Microscopic Localization of Neurotensin Binding Sites in the Midbrain Tegmentum of the Rat. I. Ventral Tegmental Area and Interfascicular Nucleus
}

\author{
Corinne Dana, ${ }^{1}$ Micheline Vial, ${ }^{1}$ Kathleen Leonard,' ${ }^{2}$ Alain Beauregard, ${ }^{2}$ Patrick Kitabgi, ${ }^{3}$ Jean-Pierre Vincent, ${ }^{3}$ \\ William Rostène, ${ }^{1}$ and Alain Beaudet ${ }^{2}$ \\ 'INSERM U-55, Hôpital St. Antoine, 75012 Paris, France, ²Laboratory of Neuroanatomy, Montreal Neurological Institute, \\ McGill University, Montreal, Quebec H3A 2B4 Canada, and ${ }^{3}$ Centre de Biochimie du CNRS, Université de Nice, 06034 \\ Nice Cedex, France
}

The distribution of specifically labeled neurotensin (NT) binding sites was examined by light and electron microscopic radioautography in the ventral tegmental area (VTA) and nucleus interfascicularis of the rat following incubation of lightly prefixed midbrain slices with the monoiodinated ligand, ${ }^{125} \mid-\left(\mathrm{Tyr}_{3}\right)$-NT. Film radioautograms of whole ${ }^{125 \mid-N T}$ incubated slices exhibited intense NT displaceable binding throughout the VTA and interfascicular nucleus. In light microscopic radioautographs from $1-\mu \mathrm{m}$-thick sections taken from the surface of the slices, the label was found to be present both inside and outside neuronal perikarya. Probability circle analysis of silver grain distribution in electron microscopic radioautographs confirmed that a significant proportion $(>20 \%)$ of the specifically labeled binding sites was intraneuronal. The frequent association of these sites with profiles of rough endoplasmic reticulum or Golgi apparatus suggested that they corresponded in part to receptors undergoing synthesis and/or glycosylation. The remainder was associated with neuronal and/or glial plasma membranes, as attested by comparing the distribution of grains overlying apposed cellular elements with the distribution of hypothetical grains originating from randomly distributed membrane bound radioactive sources. Although the resolution of the technique did not make it possible to ascribe labeled membrane-bound receptors to either one of the apposed plasma membranes, their frequent association with interfaces involving the plasmalemma of perikarya and dendrites, together with the occurrence of silver grain alignments along the membrane of certain somata and dendrites suggested that a proportion of them was associated with the perikarya and dendrites of a subpopulation of ventral tegmental neurons. Interestingly, these perikaryal and dendritic receptors were not exclusively present on, or even concentrated opposite, abutting axon terminals but instead were more or less evenly distributed along the plasma mem-

\footnotetext{
Received May 17, 1988; revised Dec. 20, 1988; accepted Jan. 4, 1989.

Supported by the Parkinson Foundation of Canada, I.N.S.E.R.M., MRT (85C-1139), and a France-Quebec exchange program. We thank Charles Hodge for photographic work, Margot Oeltzschner for preparing the line drawings, and Beverley Lindsay for typing the manuscript. Alain Beaudet is the recipient of a Scientist Award from the Medical Research Council of Canada.

Correspondence should be addressed to Dr. Alain Beaudet, Neuroanatomy Laboratory, Montreal Neurological Institute, 3801 University Street, Montreal, Quebec H3A 2B4, Canada.

Copyright (C) 1989 Society for Neuroscience $0270-6474 / 89 / 072247-11 \$ 02.00 / 0$
}

brane. Only an exceedingly small proportion was found to be associated with synaptic junctions. Such a low incidence makes it unlikely that only the synapse-linked binding sites correspond to functional receptors. On the contrary, the dispersion of labeled receptors seen here along the plasma membrane of presumptive dopamine neurons suggests that NT acts mainly in a paracrine or parasynaptic fashion in the ventral midbrain tegmentum.

Neurotensin (NT) is a tridecapeptide originally isolated from bovine hypothalamus by Carraway and Leeman (1973), and subsequently identified in the CNS of all vertebrate classes, including mammals (Carraway and Leeman, 1976; Uhl and Snyder, 1976; Kobayashi et al., 1977; Cooper et al., 1981; Emson et al., 1982; Manberg et al., 1982). Immunohistochemical studies in the rat have revealed the presence, within the substantia nigra (SN), pars compacta, and the ventral tegmental area of Tsai (VTA), of a moderate to dense network of NTcontaining perikarya and fibers coextensive and/or intermingled with dopamine (DA)-containing neurons of groups A9 and A10, respectively (Uhl et al., 1977b, 1979; Jennes et al., 1982; Hökfelt et al., 1984; Kalivas, 1984; Emson et al., 1985). Several lines of biochemical, electrophysiological, and pharmacological evidence support the view that NT is involved in the regulation of these midbrain DA cells. Microinjections of NT into the VTA elicit motor responses characterized by an increase in locomotion, sniffing, and rearing (Kalivas et al., 1981, 1983; Kalivas, 1985; Cador et al., 1985) that are blocked by DA antagonists and correlated with an increase in DA turnover in mesolimbic terminal fields (Kalivas et al., 1983). Injection of NT into the SN or the VTA produces hypothermia, which also can be blocked by DA antagonists (Kalivas et al., 1982, 1985; Kalivas, 1984). Both in vivo and in vitro application of NT or of its analog xenopsin within the $\mathrm{SN}$ or the VTA induces a marked increase in the firing rate of a subset of physiologically identified DA neurons (Andrade and Aghajanian, 1981; Pinnock, 1985; Bischoff et al., 1987) and selectively attenuates the response of midbrain DA neurons to microiontophoretically injected DA (Shi and Bunney, 1987). Finally, local perfusion of the SN with NT evokes an immediate, $\mathrm{Ca}^{2+}$-dependent release of DA with a concomitant increase in DA metabolites (Myers and Lee, 1983).

In keeping with the generation of these physiological effects is the presence, throughout the ventral midbrain, of specific NT high-affinity binding sites (Young and Kuhar, 1981; Quirion et 
al., 1982; Uhl, 1982) exhibiting pharmacological characteristics of functional receptors (Kitabgi et al., 1977; Uhl et al., 1977a). Light microscopic radioautographic investigations have shown NT binding sites to be mainly concentrated over the perikarya and dendrites of SN, pars compacta, and VTA neurons (Moyse et al., 1987; Waters et al., 1987). The latter have been suggested to correspond to DA cells on the basis of the substantial decrease in NT binding observed in the midbrain tegmentum following local injection of the selective cytotoxic drug 6-hydroxydopamine (6-OHDA; Palacios and Kuhar, 1981; Quirion, 1983; Quirion et al., 1985; Hervé et al., 1986) or systemic administration of 1-methyl-4-phenyl-1,2,3,6-tetrahydropyradine (MPTP; Waters et al., 1987). Formal demonstration of a direct localization of NT receptors on the perikarya and dendrites of DA cells was recently provided in the rat by a combined radioautographic and immunohistochemical investigation, which showed a selective association of NT binding sites with approximately $95 \%$ and $80-90 \%$ of tyrosine hydroxylase-immunoreactive neurons in the SN and the VTA, respectively (Szigethy and Beaudet, 1989). The fine structural distribution of NT receptors on these cells, however, remains obscure. In the present study, we have examined the electron microscopic radioautographic distribution of specifically labeled NT binding sites in the VTA, including the nucleus paranigralis, parabrachialis pigmentosis, and linearis rostralis (see Phillipson, 1979; Swanson, 1982), and nucleus interfascicularis of the rat. The fine structural distribution of NT receptors in the SN will be the subject of a separate publication (Beaudet et al., unpublished observations).

\section{Materials and Methods}

Labeling procedures. Adult male Sprague-Dawley rats (180-200 gm) were anesthetized with sodium pentobarbital (Somnotol, $0.12 \mathrm{ml} / 100$ $\mathrm{gm}$ ) and perfused through the ascending aorta with an ice-cold mixture of $1 \%$ tannic acid, $0.75 \%$ paraformaldehyde, and $0.1 \%$ glutaraldehyde in $0.1 \mathrm{M}$ phosphate buffer (Hamel and Beaudet, 1984). In a first series of experiments designed to assess the effects of this prefixation procedure on NT binding parameters, the brains were frozen immediately after perfusion by immersion in isopentane at $-50^{\circ} \mathrm{C}$ for $10 \mathrm{~min}$. Twenty$\mu \mathrm{m}$-thick coronal sections from the midbrain tegmentum were cut on a cryostat, mounted on gelatin-subbed slides, and incubated with 0.1 $\mathrm{nm}^{125}$ I-NT as described below. At the end of the incubation, the sections were rinsed in cold buffer, air-dried, scraped off the slides with a razor blade, and counted in a Packard beta rack gamma counter. For controls, sections from unperfused rat brains were incubated and processed in parallel.

For electron microscopy, the perfused brains were rapidly dislodged from the skull and the entire midbrain tegmentum blocked on ice and sliced on a vibrating microtome (Vibratome) from the caudal pole of the interpeduncular nucleus caudally to the midmammillary area rostrally. Slices (70- to 75- $\mu \mathrm{m}$-thick) were immediately incubated with 0.1 $\mathrm{nm}$ monoiodo ${ }^{125} \mathrm{I}-\mathrm{Tyr}_{3}-\mathrm{NT}(2000 \mathrm{Ci} / \mathrm{mmol}$; for details on iodination and purification, see Sadoul et al., 1984) in $50 \mathrm{~mm}$ ice-cold Tris- $\mathrm{HCl}$ buffer, pH 7.4, supplemented with $5 \mathrm{mM} \mathrm{MgCl}_{2}, 0.2 \% \mathrm{BSA}, 2 \times 10^{-3}$ $M$ Bacitracin, and $0.25 \mathrm{~mm}$ sucrose for $60 \mathrm{~min}$ at $4^{\circ} \mathrm{C}$. Every third slice was incubated with ${ }^{125} \mathrm{I}-\mathrm{NT}$ as above, but in the presence of $500 \mathrm{nM}$ nonradioactive NT for determination of nonspecific binding. At the end of the incubation, all slices were rinsed in 4 consecutive ice-cold buffer baths $(2 \mathrm{~min} / \mathrm{bath})$ and fixed for $30 \mathrm{~min}$ at $40^{\circ} \mathrm{C}$ by immersion in $4 \%$ glutaraldehyde in $50 \mathrm{~mm}$ phosphate buffer. Every second slice was then rapidly rinsed in distilled water, mounted on a gelatinized glass slide, and air-dried at room temperature. The remaining slices were postfixed for $1 \mathrm{hr}$ at room $t_{0}$ in $2 \% \mathrm{OsO}_{4}$, dehydrated in ethanols, and flat-embedded in Epon between 2 plastic coverslips after measuring their radioactivity content.

Radioautographic procedures. Slide-mounted slices were radioautographed by apposition against tritium-sensitive film (Ultrofilm LKB) inside X-ray cassettes, at $4^{\circ} \mathrm{C}$. The films were developed after $4 \mathrm{~d}$ of exposure using Kodak LX developer and projected against camera lucida drawings of the corresponding adjacent plastic-embedded slices to enable precise sampling of areas containing high receptor densities (Fig. 1). Epon-embedded slices were trimmed accordingly, reembedded in Beem capsules and cut on a Reichert-Young ultramicrotome.

Semithin sections ( $1 \mu \mathrm{m}$ thick) were first taken from the surface of each slice, collected on glass slides, coated by dipping into Kodak NTB-2 nuclear emulsion diluted $1: 1$, and exposed for 6 weeks at $4^{\circ} \mathrm{C}$. These light microscopic radioautographs were developed in freshly prepared D19 (4 min at $\left.17^{\circ} \mathrm{C}\right)$, stained with toluidine blue, and examined with a Leitz Orthoplan microscope. Ribbons of silver sections were then taken from the same blocks, deposited on parlodion-coated slides, stained with uranyl acetate and lead citrate, carbon-coated, and radioautographed by dipping into Ilford L4 emulsion diluted 1:4. After 8 weeks of exposure, these electron microscopic radioautographs were developed in D19 ( 1 min at $20^{\circ} \mathrm{C}$ ), collected on 150-mesh copper grids, and examined with a JEOL $1200 \mathrm{EX}$ electron microscope after thinning the parlodion membrane in isoamyl acetate.

Analysis of electron microscopic radioautograms. Quantitative analysis of electron microscopic radioautographs was carried out in 7 thin sections from 3 different animals. Four of these sections were from slices incubated with ${ }^{125}$ I-NT alone: 3 from the VTA ( 1 per animal), and one from the interfascicular nucleus (Fig. 1). The other 3 were from slices incubated in the presence of nonradioactive NT ( 1 per animal). All sections were systematically scanned and every labeled site photographed at an initial magnification of 10,000. The distribution of silver grains was analyzed using a probability circle method modified from Williams (1969). The location of radioactive sources giving rise to "shared" grains (see below) was then extrapolated by line source analysis.

For probability circle analysis, a 50\% resolution circle (diameter, 3.4 $\times$ half-distance (HD); HD $=90 \mathrm{~nm}$; see Blackett and Parry, 1977, Salpeter et al., 1978), drawn on a transparent overlay, was centered over each grain $(n=1892)$ and the structure (exclusive grains) or combination of structures (shared grains) included within this circle recorded and tabulated. A population of uniformly distributed hypothetical grains ( $n$ $=6262$ ) was then generated by superimposing over the same micrographs a regular array of resolution circles of the same diameter as those used to score real grains. As for real grains, the structure(s) present within each circle was recorded and tabulated.

To determine the distribution of specific binding, the distribution of real grains in sections incubated with an excess of nonradioactive NT was first corrected so as to match the hypothetical grain distribution in corresponding slices incubated with ${ }^{25}$ I-NT (so as to reflect the distribution of nonspecific binding in the very section in which the distribution of total binding was being analyzed), multiplied by the appropriate nonspecific over total binding ratio (derived from the radioactivity content of the 2 slices), and then subtracted from that observed in sections incubated with ${ }^{125}$ I-NT alone.

To reduce the number of compartments in the analysis, grains originally ascribed to compartments containing 3 structures or more were redistributed within compartments containing only 2 , according to the respective labeling frequency of each pair of structures seen within the resolution circle. Thus, for instance, grains originally classified as belonging to the compartment "dendrite-axon-glia" were redistributed within compartments "dendrite-axon," "axon-glia," and "dendrite-glia" proportionally to the original labeling frequency of each of these 3 compartments. In addition, grains overlying both identified and unidentified profiles were reascribed to compartments containing identified elements according to the frequency with which these identified compartments were originally labeled.

The distribution of real grains (total, specific, and nonspecific) was compared with that of hypothetical grains using a $\chi^{2}$ analysis. The distribution of specific binding was then compared in the same way to that of nonspecific binding. Finally, a labeling index was obtained for each compartment by dividing the number of real grains by that of hypothetical grains.

The line source analysis was carried out on 300 shared grains chosen at random from material incubated with ${ }^{125}$ I-NT alone. The distance separating the center of each grain from the closest plasma membrane was measured and expressed in HD units. A frequency distribution histogram was generated by plotting the number of silver grains as a function of their distance from the closest plasma membrane. This distribution was then compared by $\chi^{2}$ analysis to that of a population of grains that might have arisen from a uniform population of mem- 

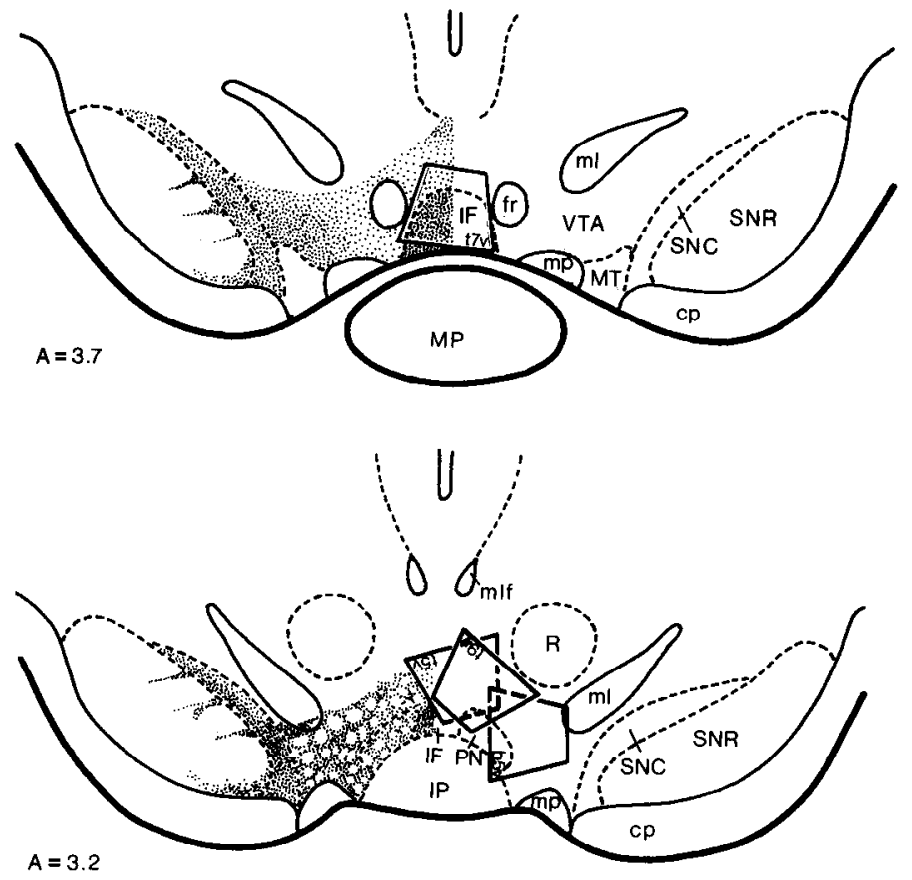

Figure 1. Schematic drawings of 2 different coronal sections from the rat midbrain tegmentum. Nomenclature and anterior posterior coordinates after Paxinos and Watson (1986). At left, black stiplings mark the distribution and density of ${ }^{125}$ I-NT-labeled binding sites. Trapezoids outline areas selected for electron microscopic examination. Blanks were sampled at approximately the same level as the corresponding totals. Abbreviations: $c p$, cerebral peduncle; $f r$, fasciculus retroflexus; $m l$, medial lemniscus; $m l f$, medial longitudinal fasciculus; $m p$, mammillary peduncle; $I F$, interfascicular nucleus; $I P$, interpeduncular nucleus; $M P$, posterior mamillary body; $M T$, mammillary tract; $S N C$, substantia nigra, pars compacta; $S N R$, substantia nigra, pars reticulata; $P N$, paranigralis nucleus; $R$, red nucleus; $V T A$, ventral tegmental area.

brane-bound sources. This second population of hypothetical grains (distinct from that obtained using probability circles) was generated by drawing a straight line across 70 randomly selected electron micrographs and considering every point of intersection of this line with a plasma membrane as a hypothetical membrane source. Hypothetical grains were then generated from every one of these sources using ${ }^{125} I$ crossfire masks provided by Salpeter et al. (1978), and the distance scparating the center of each grain from the closest plasma membrane measured and plotted as for real grains.

\section{Results}

The kinetic parameters of ${ }^{125}$ I-NT binding to frozen midbrain sections were similar before and after perfusion fixation of the brain with a weak solution of aldehydes (Fig. 2). In both cases, specific binding reached a plateau between 60 and $120 \mathrm{~min}$. Scatchard analysis of the binding parameters yielded a linear plot with a dissociation constant $\left(K_{d}\right)$ of $9.3 \pm 0.4 \mathrm{nM}$ and a number of sites $\left(B_{m}\right)$ of $86 \pm 10 \mathrm{fm} / \mathrm{mg}$ protein.

\section{Light microscopic radioautography}

Film radioautograms from $75-\mu \mathrm{m}$-thick slices incubated with $0.1 \mathrm{~nm}{ }^{125} \mathrm{I}-\mathrm{NT}$ alone exhibited high labeling densities throughout the VTA and interfascicular nucleus, as well as within the SN, pars compacta (Fig. 3a). Rostral to the interpeduncular nucleus, labeling in the VTA was homogeneously intense, except over cross-sectioned fibers of the fasciculus retroflexus (Fig. 1, $A=3.7$ ). More caudally, the labeling appeared less homogeneous ventrolaterally, at the junction between the VTA and the medial

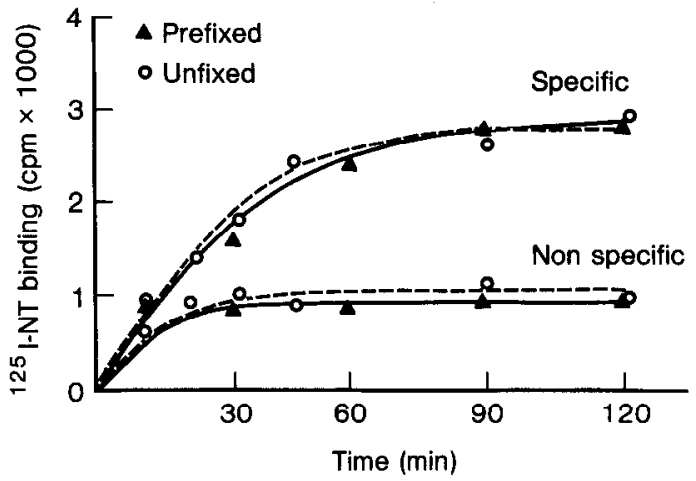

Figure 2, Effect of prefixation on the time course of ${ }^{125} \mathrm{I}-\mathrm{NT}$ binding to sections of the rat midbrain. Sections from perfusion-fixed (triangles) and fresh-frozen (circles) brains were incubated with $0.1 \mathrm{nM}{ }^{125}$ I-NT in the absence (specific binding) or in the presence (nonspecific binding) of $500 \mathrm{~nm}$ nonradioactive NT. Each point corresponds to the mean \pm SEM of 3 different determinations.

SN, due to the sparing of transtegmental fiber bundles (Fig. 1, $A=3.2$ ). The interfascicular nucleus was intensely labeled throughout its rostrocaudal extent (Figs. $1, A=3.7 ; 3 a$ ). In slices incubated with an excess of nonradioactive NT, the labeling was weak and diffusely distributed (Fig. $3 b$ ). The radioactivity content of these slices was $72 \pm 4 \%$ less than that of slices incubated with ${ }^{125}$ I-NT alone.

Light microscopic radioautograms of semithin sections taken from the surface of slices incubated with ${ }^{125}$ I-NT alone exhibited a labeling pattern comparable to that observed in film radioautographs of whole slices (Fig. 4a). At high magnification, silver grains were found to predominate over the neuropil (Fig. $4 b$ ). However, many were also detected inside and/or alongside nerve cell bodies and their proximal processes (Fig. 4, b, c). Others were associated with endothelial cells and pericytes surrounding interparenchymal capillaries. In sections incubated with an excess of nonradioactive NT, silver grains were scarce and mainly associated with capillary walls.

\section{Electron microscopic radioautography}

The electron microscopic distribution of silver grains, as assessed by probability circle analysis, was significantly different in sections incubated with ${ }^{125} \mathrm{I}-\mathrm{NT}$ alone (total binding) than in sections incubated with an excess of nonradioactive NT ( $p \leq$ 0.001 ). Both distributions were, in turn, significantly different from that of hypothetical grains randomly generated within the same sections $(p \leq 0.001)$. After subtraction of nonspecific from total hinding, $36 \%$ of silver grains were ascribed to single neuronal or glial structures (exclusive grains; Table 1) and $48 \%$ to 2 structures or more (shared grains; Table 2). The remaining grains overlaid structures that could not be positively identified.

More than $60 \%$ of exclusive grains (20\% of total; Table 1) were found over cell bodies and dendrites. Nerve cell bodies, however, showed a higher labeling index than dendrites (1.3 vs 0.6). Labeled dendrites included shafts (Fig. $5 a$ ), branches, and spines. Most exhibited a light cytoplasmic matrix and contained mitochondria, cisterns of endoplasmic reticulum, ribosomes, lysosomes, and axially oriented microtubules (Fig. 5a). A few also showed scattered small clear and/or large granular vesicles.

Almost $20 \%$ of exclusive grains ( $7 \%$ of total; Table 1 ) were associated with glia. More than $2 / 3$ of these overlaid myelin lamellae. The others were mainly found over astrocytic processes 


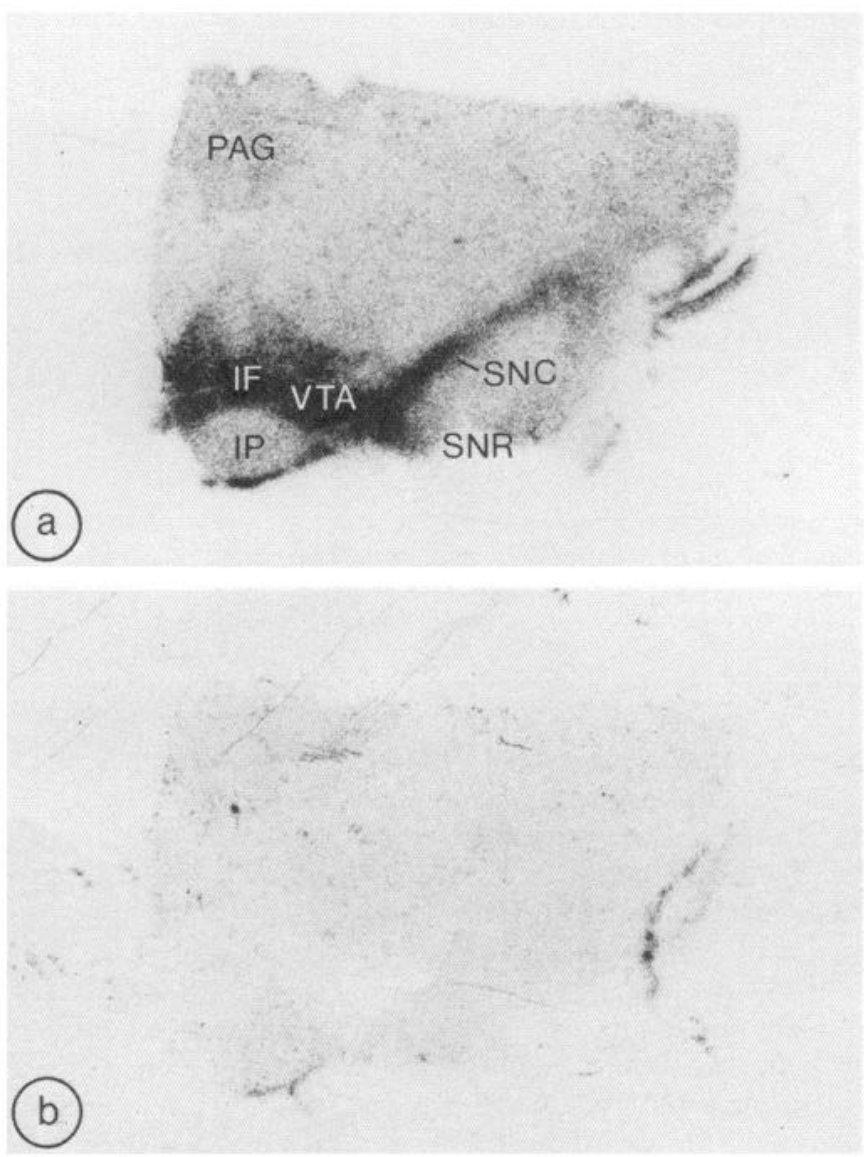

Figure 3. Radioautographic distribution of bound ${ }^{125}$ I-NT molecules in $75-\mu \mathrm{m}$-thick vibratome-cut sections of the rat midbrain incubated with $0.1 \mathrm{nM}^{125} \mathrm{I}-\mathrm{NT}$ in the absence (total binding: $a$ ) or in the presence (nonspecific binding: $b$ ) of a 5000-fold excess of nonradioactive NT. After incubation, sections were rinsed, fixed in $4 \%$ glutaraldehyde, and radioautographed by apposition to tritium-sensitive film. An intense, NT-displaceable binding is apparent over the ventral tegmental area $(V T A)$, nucleus interfascicularis $(I F)$, and substantia nigra, pars compacta $(S N C)$. Section corresponds approximately to level $A=3.2$ in Figure 1. IP, interpeduncular nucleus; $P A G$, periaqueductal gray; $S N R$, substantia nigra, pars reticulata.

(Fig. $6 b$ ). Exclusive grains were also found inside myelinated axons ( $4.4 \%$ of total; Table 1$)$ but with a lower frequency than expected from a uniform distribution. Although most myelinated axonal profiles showed only 1 or 2 silver grains, a few were relatively heavily labeled (i.e., exhibited 3 grains or more, Fig. $5 b$ ). Finally, approximately $4 \%$ of "specific" grains were associated with axon terminals as compared with $11 \%$ of hypothetical grains (Table 1).

Approximately $43 \%$ of shared grains overlaid neuronal and/ or glial interfaces involving an axon terminal ( $20 \%$ of total; Table 2). These terminals were variable in size and shape (Figs. $5 c ; 6, a, c ; 7 a$ ). All contained small and mostly rounded agranular synaptic vesicles. In some cases, the vesicles almost filled the terminal (Figs. $6 c, 7 a$ ), whereas in others they were mainly clustered next to the membrane (Figs. $5 c, 6 a$ ). Interfaces between terminals and dendrites accounted for more than $15 \%$ of shared grains (Figs. $5 c, 6 a$ ). Only a small proportion of these $(\simeq 2 \%$ of shared grains) exhibited a synaptic differentiation in the plane of section. When present, synaptic differentiations were usually of the asymmetrical variety (Fig. $5 c$ ). Appositions between axon
Table 1. Radioautographic distribution of specifically labeled ${ }^{125}$ I-NT binding sites in the ventral tegmental area: exclusive grains

\begin{tabular}{lrrl} 
Compartment $^{a}$ & Real grains & \multicolumn{1}{c}{$\begin{array}{l}\text { Hypothetical } \\
\text { grains }^{c}\end{array}$} & Real/Hyp \\
\hline Somata & $10.2 \pm 1.2$ & $8.0 \pm 1.0$ & 1.3 \\
Dendrites & $10.0 \pm 4.0$ & $15.4 \pm 1.1$ & 0.6 \\
Axon terminals & $4.2 \pm 1.7$ & $11.0 \pm 1.1$ & 0.4 \\
Myelinated axons & $4.4 \pm 1.6$ & $9.3 \pm 4.2$ & 0.5 \\
Glia & $6.9 \pm 1.9$ & $5.4 \pm 1.3$ & 1.3 \\
Blood vessels & $0.6 \pm 0.5$ & $0.9 \pm 0.2$ & 0.6 \\
\hline
\end{tabular}

"Compartments containing more than $0.5 \%$ of "specific" grains.

${ }^{b}$ After subtraction of nonspecific binding as described in Materials and Methods. - Expressed as a percentage of total \pm SEM. Distribution of real grains significantly different from that of hypothetical (Hyp) grains at $p<0.001$.

terminals and unmyelinated axons accounted for almost as many shared grains as terminal/dendrite appositions but showed a substantially higher labeling index (Table 2). Also enriched over terminal/dendrite appositions were terminal/soma (Fig. $6 c$ ) and terminal/glia compartments (Table 2). The latter mainly implicated protoplasmic and fibrous astrocytes but also occasional oligodendrocytic profiles.

Labeled interfaces involving dendrites accounted for $34 \%$ of shared grains ( $16 \%$ of total; Table 2$)$. In approximately half of these, the adjoining element was an axon terminal (see above). However, compartments in which dendrites were associated with unmyelinated axons (Fig. 7b), other dendrites (Figs. $5 a$, $7 a$ ), or astrocytic glia (Figs. $5 a, 6 b, 7 b$ ) all showed higher labeling indexes than terminal/dendrite associations (Table 2). Occasionally, large dendritic profiles were seen to be labeled at several loci along their plasma membrane (Figs. 5a, 6b, 7).

Compartments involving cross-sectioned or longitudinally oriented unmyelinated axons accounted for approximately $36 \%$ of shared grains ( $17 \%$ of total; Table 2). Most of these axons were small and showed a dense cytoplasmic matrix (Fig. 7a). They usually ran in tight bundles with other myelinated and/or

Table 2. Radioautographic distribution of specifically labeled ${ }^{125}$ I-NT binding sites in the ventral tegmental area: shared grains

\begin{tabular}{llll} 
Compartment $^{a}$ & Real grains $^{h, c}$ & $\begin{array}{l}\text { Hypothetical } \\
\text { grains }^{c}\end{array}$ & Real/Hyp \\
\hline Terminal/terminal & $1.9 \pm 1.3$ & $2.1 \pm 1.6$ & 0.9 \\
Terminal/dendrite & $7.2 \pm 2.2$ & $8.4 \pm 1.6$ & 0.8 \\
Terminal/axon & $5.6 \pm 3.5$ & $3.0 \pm 0.5$ & 1.9 \\
Terminal/soma & $0.5 \pm 0.3$ & $0.4 \pm 0.2$ & 1.2 \\
Terminal/glia & $4.7 \pm 1.8$ & $2.3 \pm 0.6$ & 2.0 \\
Dendrite/dendrite & $1.0 \pm 0.4$ & $0.6 \pm 0.4$ & 1.6 \\
Dendrite/axon & $3.9 \pm 1.6$ & $3.9 \pm 0.9$ & 1.0 \\
Dendrite/glia & $3.7 \pm 1.2$ & $2.8 \pm 0.5$ & 1.3 \\
Axon/axon & $5.8 \pm 1.3$ & $4.8 \pm 1.4$ & 1.2 \\
Axon/soma & $0.4 \pm 0.5$ & $0.0 \pm 0.0$ & \\
Axon/glia & $1.3 \pm 1.2$ & $2.8 \pm 0.9$ & 0.4 \\
Glia/soma & $1.0 \pm 0.7$ & $0.3 \pm 0.1$ & 3.3 \\
Glia/myelinated axon & $9.7 \pm 5.4$ & $10.4 \pm 2.5$ & 0.9
\end{tabular}

${ }^{a}$ Unmyelinated axons referred to as axons.

${ }^{\circ}$ After subtraction of nonspecific binding as described in Materials and Methods. ' Expressed as a percentage of total \pm SEM. Distribution of real grains significantly different from that of hypothetical (Hyp) grains at $p<0.001$. 

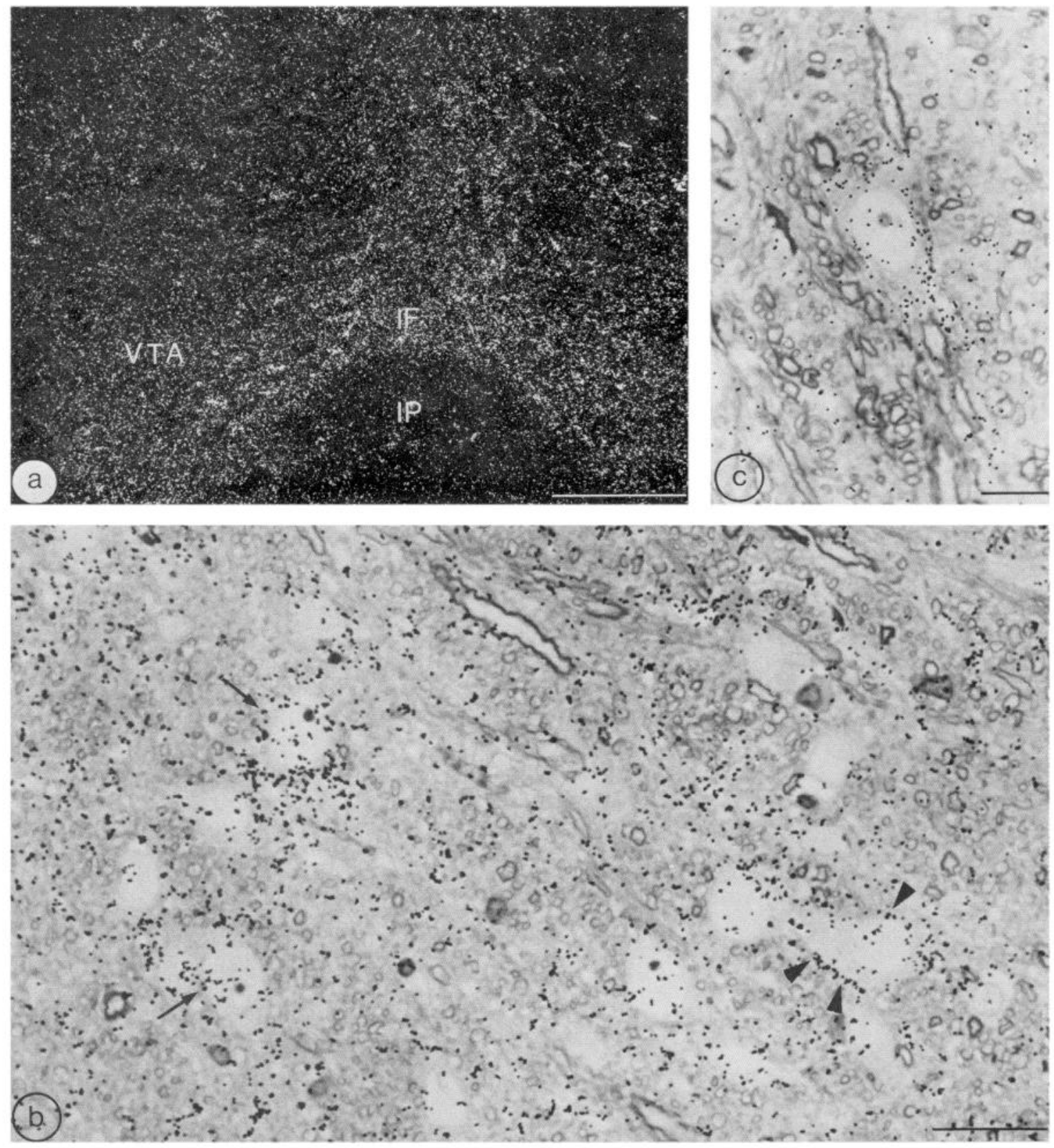

Figure 4. Distribution of radiolabeled binding sites in 1- $\mu \mathrm{m}$-thick Epon-embedded sections taken from the surface of ${ }^{125}$ I-NT-incubated vibratome slices. $a$, Dark-field micrograph of the ventral midbrain tegmentum showing a dense concentration of label over nucleus interfascicularis $(I F)$ and in between transtegmental fiber bundles in the parabrachialis pigmentosus segment of the VTA. Note the absence of labeling over the interpeduncular nucleus $(I P)$. Scale bar, $250 \mu \mathrm{m}$. $b$, In bright-field, labeled binding sites are detected in the form of stray silver grains scattered throughout the neuropil. Some are preferentially associated with neuronal perikarya (arrows) or run along their contour (arrowheads). Scale bar, $25 \mu \mathrm{m}$. $c$, ${ }^{125} \mathrm{I}-$ NT-labeled VTA neuron showing a selective accumulation of silver grains over its perikaryon and proximal processes. Scale bar, $15 \mu \mathrm{m}$.

unmyelinated fibers. Accordingly, axon/axon interfaces showed the highest labeling frequency of this category of shared grains (Table 2). Appositions between unmyelinated axons and axon terminals or dendrites were also enriched (Table 2; see above).

Compartments involving somatic membranes accounted for only $4 \%$ of shared grains, but all were labeled with a frequency higher than expected from the distribution of hypothetical grains (Table 2). As in the case of dendrites, certain nerve cell bodies showed several labeling foci along their plasma membrane (Fig. $6 c$ ). Only a few of these foci faced axon terminals (Fig. 6c).
Finally, almost $10 \%$ of shared grains concurrently overlaid the axolemma and innermost glial leaflets of cross-sectioned myelinated axons (glia/myelinated axon; Table 2). In many instances, these cross-sectioned axons also exhibited exclusive grains over their axoplasm.

When analyzed as a function of the grains' distance to the closest plasma membrane (line source analysis), the distribution of shared grains showed a steep decline with increasing distance from the membrane. As can be seen in Figure 8, more than $90 \%$ of the grains actually fell within $1.7 \mathrm{HD}$ (i.e., within the radius 

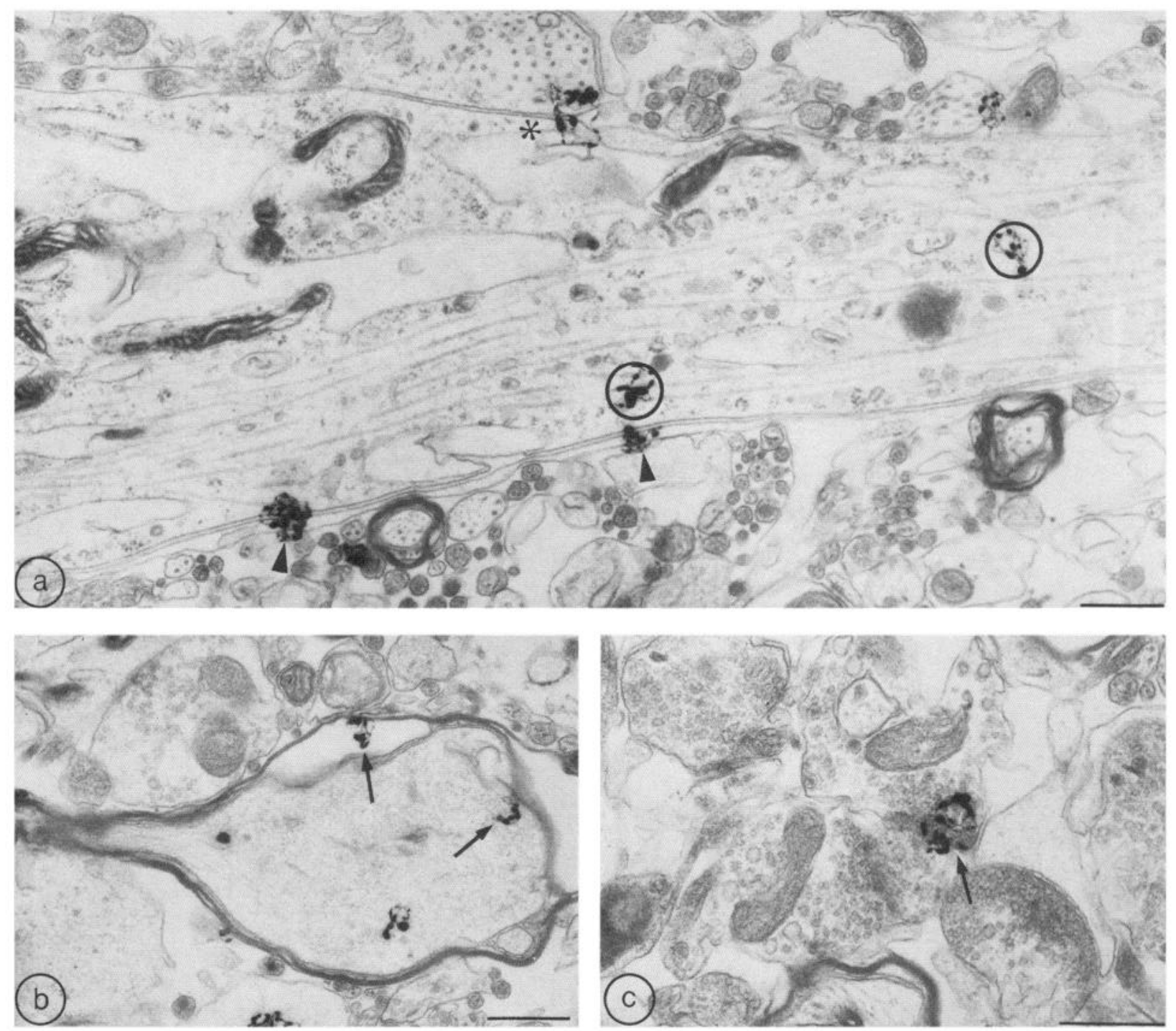

Figure 5. Electron microscopic radioautograms from sections of the VTA incubated with $0.1 \mathrm{~nm}{ }^{125}$ I-NT. $a$, Large ${ }^{125}$ I-NT-labeled dendritic shaft. The 2 grains surrounded by a resolution circle (of the size used for our statistical analysis) are located over the cytoplasm and as such were classified as "exclusive." All other grains are "shared," i.e., overlie the plasma membrane. One of them encompasses a second cross-sectioned dendrite (asterisk), whereas 2 others face a thin glial leaflet (arrowheads). Scale bar, $0.5 \mu \mathrm{m}$. $b$, Cross section of a ${ }^{125} \mathrm{I}-\mathrm{NT}$-labeled myelinated axon. Two of the grains are shared (arrows), in that their resolution circle overlaps both the axon and the myelin sheath. Scale bar, $0.5 \mu \mathrm{m} . c$, Labeled axodendritic contact. A synaptic density may be discerned underneath the labeling (arrow). Scale bar, $0.5 \mu \mathrm{m}$.

of a resolution circle) of the membrane. This distribution was not significantly different from that of hypothetical grains generated from fictive random membrane-bound radioactive sources in the same material (Fig. 8).

The fine structural distribution of nonspecific binding is summarized in Table 3 . This distribution was significantly different from that of hypothetical grains generated within the same sections. A large proportion of nonspecifically bound ${ }^{125} \mathrm{I}-\mathrm{NT}$ was associated with glia-containing compartments ( $22 \%$ of exclusive grains; $75 \%$ of shared grains; Table 3 ). Moreover, nearly all of these compartments showed high labeling indexes (Table 3). A substantial amount of nonspecific labeling ( $3 \%$ of total; Table 3 ) was associated with intraparenchymal capillaries. The latter compartment was also found to be enriched by comparison with hypothetical grains.

\section{Discussion}

\section{Methodology}

The kinetics of ${ }^{125}$ I-NT binding observed here in sections of the rat midbrain were comparable to those previously reported for ${ }^{3} \mathrm{H}-$ or ${ }^{125} \mathrm{I}-\mathrm{NT}$ in rat brain sections or homogenates (Kitabgi et al., 1977; Uhl et al., 1977a; Young and Kuhar, 1981; Quirion et al., 1982; Moyse et al., 1987). Inhibition of ${ }^{125}$ I-NT binding by native NT yielded a linear Scatchard plot, suggesting that under our experimental conditions ${ }^{125}$ I-NT had bound to a single population of sites. Pharmacological studies have demonstrated that ${ }^{125}$ I-NT binds, in fact, to 2 distinct classes of sites in rat brain with affinities that exhibit a 50 -fold difference at room $t$ 。 but are similar at $4^{\circ} \mathrm{C}$ (Mazella et al., 1983; Sadoul et al., 1984; Kitabgi et al., 1985; Schotte et al., 1986). Binding to the low- 

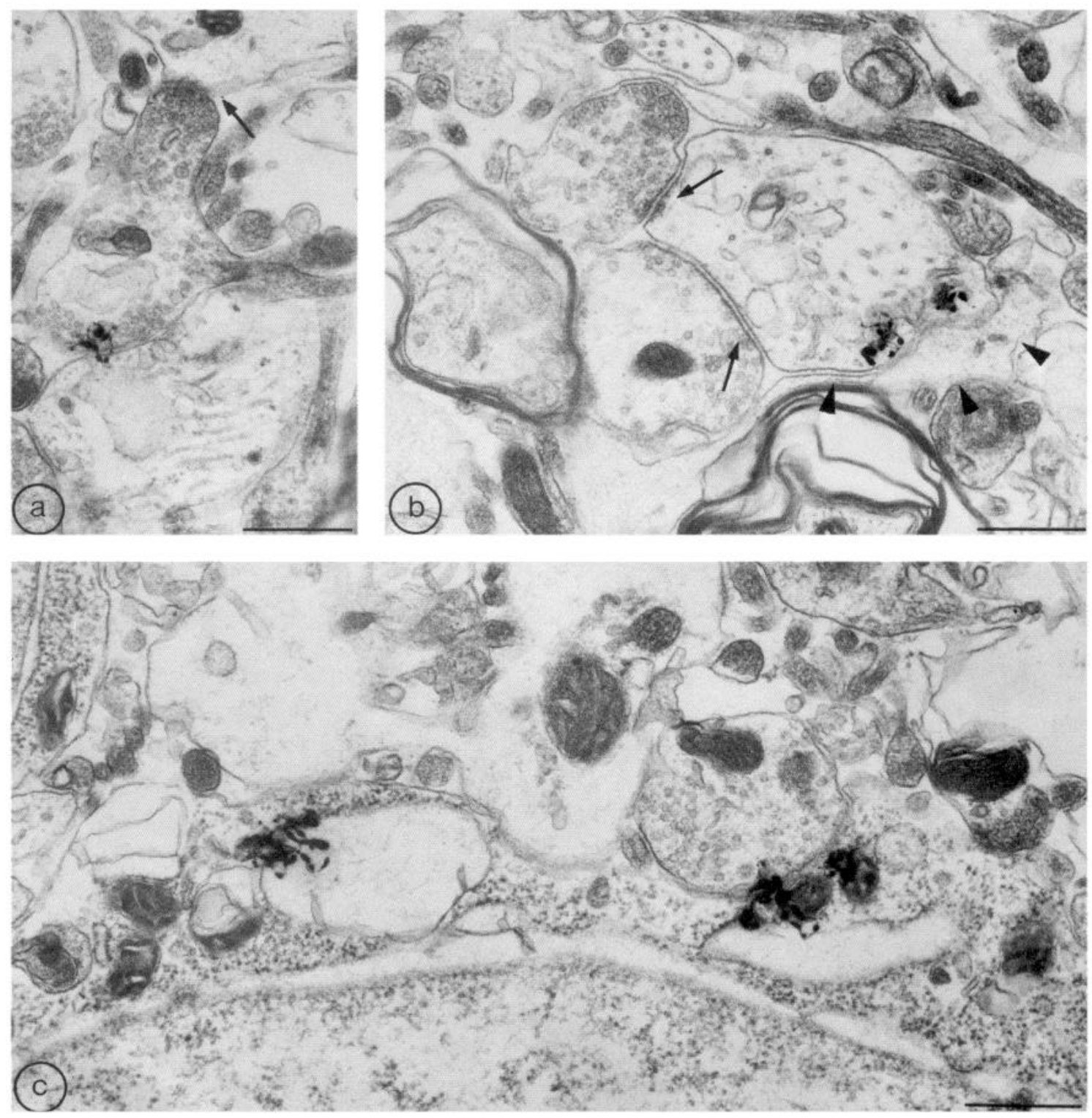

Figure 6. Electron microscopic radioautograms from VTA sections incubated with $0.1 \mathrm{~nm}{ }^{125}$ I-NT. $a$, ${ }^{125}$ I-NT-labeled axodendritic apposition. Clustered small clear synaptic vesicles but no synaptic differentiation are visible at the site of contact. Note that the labeled axon terminal makes an unlabeled, asymmetrical synapse on another dendrite (arrow). Scale bar, $0.5 \mu \mathrm{m}$. $b$, The resolution circles associated with these 2 silver grains encompass the plasma membranes of a cross-sectioned dendritic shaft and of an adjoining astrocytic process (arrowheads). Neither includes one of the abutting synaptic terminals (arrows). Scale bar, $0.5 \mu \mathrm{m}$. $c$, Segment of a ${ }^{125} \mathrm{I}-\mathrm{NT}$-labeled perikaryon. Two of the silver grains face an abutting axon terminal filled with small, clear synaptic vesicles. Note the absence of synaptic thickening at the site of contact. The other 2 grains lie close to the edge of the cell, but their resolution circles do not impinge upon the plasma membrane. Scale bar, $0.5 \mu \mathrm{m}$.

affinity site is unlikely to have accounted for much of the labeling detected in the present study, however, since recent radioautographic data have indicated that most if not all of NT binding sites labeled within the VTA under conditions comparable to ours correspond to the high-affinity sites (Kitabgi et al., 1987; Szigethy and Beaudet, 1989).

Prefixation of the brain with weak concentrations of aldehydes affected neither the affinity nor the capacity of ${ }^{125}$ I-NT binding to rat midbrain sections. Accordingly, the topographic distribution of bound ${ }^{125} \mathrm{I}-\mathrm{NT}$ molecules in $75-\mu \mathrm{m}$-thick prefixed slices of the midbrain tegmentum, as assessed here by film radioautography, was comparable to that previously documented in 20to $30-\mu \mathrm{m}$-thick unfixed frozen sections of the same region (Moyse et al., 1987). Nonspecific binding was somewhat higher in aldehyde-prefixed than in fresh-frozen material, presumably because of poorer penetration of buffer rinses and artifactual cross-linking of the ligand by free aldehyde groups.

Earlier studies have shown that postfixation of ${ }^{125}$ I-NT-labeled tissue sections with high concentrations of glutaraldehyde ensured irreversible cross-linking of bound ${ }^{125}$ I-NT molecules (Moyse et al., 1987). The yield of this cross-linking reaction was found to be on the order of $70 \%$ and homogeneous across brain regions (Moyse et al., 1987). In the present study, the radioautographic distribution of ${ }^{125}$ I-NT-labeled binding sites in semithin sections from histoprocessed, plastic-embedded material was similar to that observed in fresh-frozen sections from the 


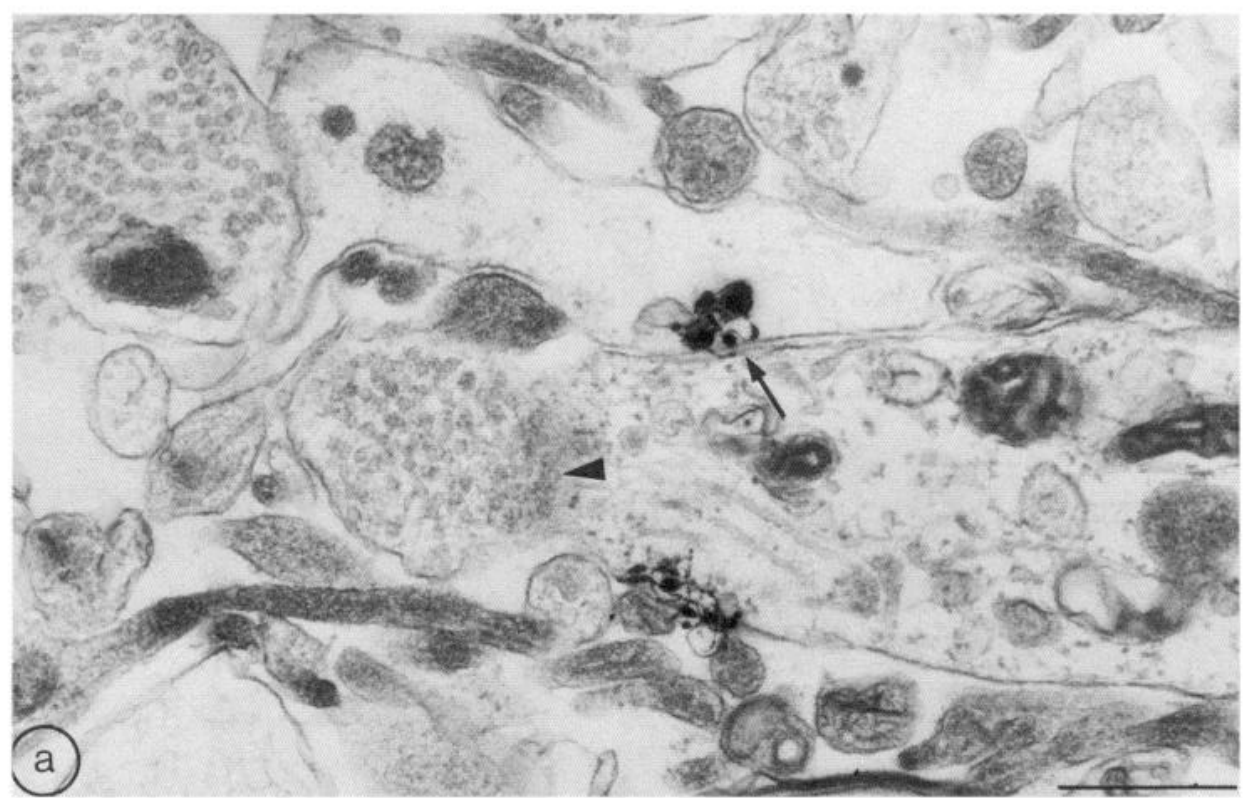

Figure 7. Electron microscopic radioautograms from VTA sections incubated with $0.1 \mathrm{~nm}{ }^{125} \mathrm{I}-\mathrm{NT}$. Two cross-sectioned dendritic shafts showing 2 different labeling foci along their plasma membrane. Each receives one abutting synaptic terminal (arrowheads), neither of which appears to be labeled. $a$, One of the grains encompasses the plasma membrane of an adjacent dendrite (arrow) and the other that of small unmyelinated axons. $b$, One of the grains overlies the plasma membrane of an abutting axon terminal (arrow) and the other that of an astroglial process. Scale bar, $0.5 \mu \mathrm{m}$.

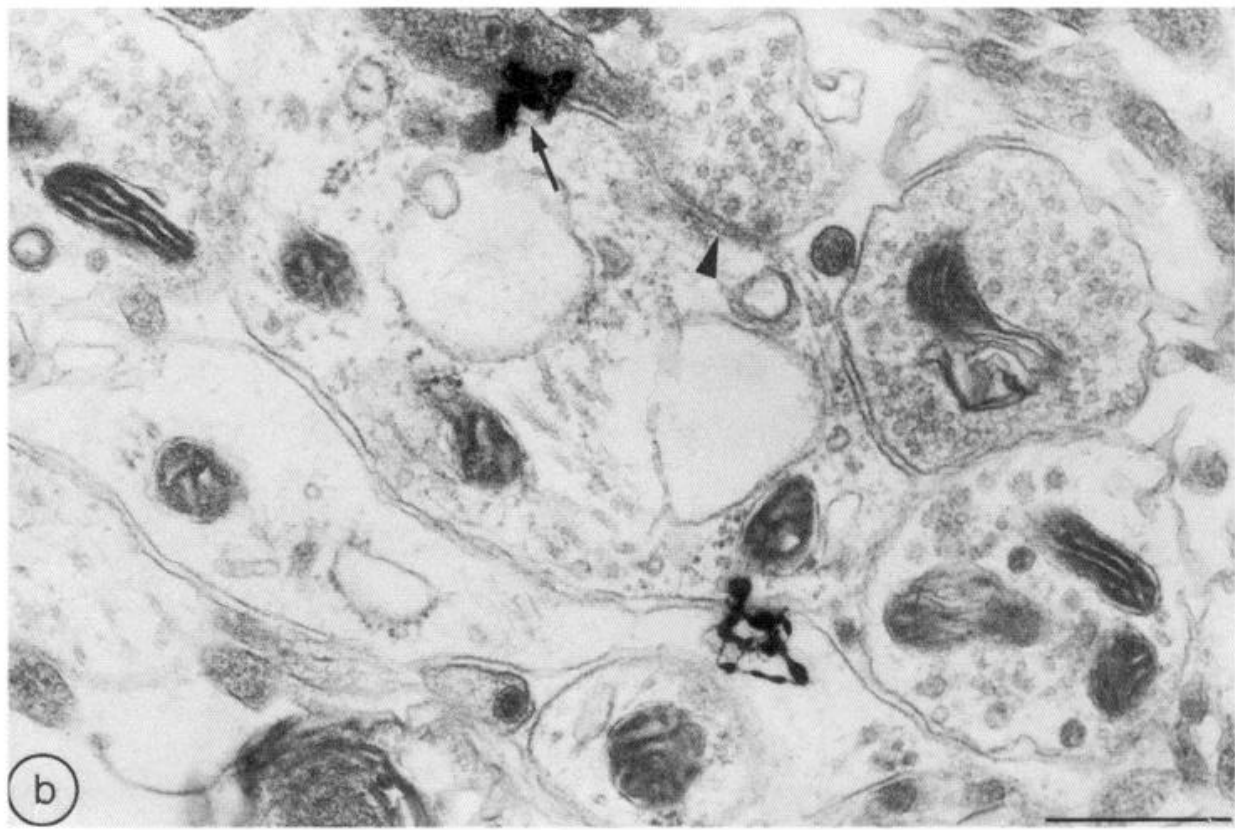

same areas, confirming that ${ }^{125} \mathrm{I}-\mathrm{NT}$ molecules had been crosslinked prior to dissociation from their specific binding sites and were thereby amenable to electron microscopic visualization.

\section{Light microscopic distribution of ${ }^{125} I-N T$ labeled binding sites}

At the light microscopic level, ${ }^{125} \mathrm{I}-\mathrm{NT}$-labeled binding sites were detected both over and between neuronal perikarya, as previously observed in fresh-frozen sections (Moyse et al., 1987). However, whereas in frozen sections silver grains were more or less homogeneously distributed over the soma, in semithin sections they often appeared preferentially distributed at the periphery of the cell as if originating from membrane-bound molecules. This difference could be due to the fact that intraperikaryal binding sites were less readily accessible to the ligand in $75-\mu \mathrm{m}$ thick, prefixed slices than in 20 - to $30-\mu \mathrm{m}$-thick fresh-frozen sections. In any event, the present light microscopic results suggest that NT binding sites are present both inside and on the surface of neuronal perikarya in the ventral midbrain tegmentum. Given that the vast majority of ${ }^{125}$ I-NT-labeled cells detected in the VTA were shown by combined radioautography and immunocytochemistry to contain the catecholamine biosynthetic enzyme tyrosine hydroxylase (Szigethy and Beaudet, 1989), it can reasonably be assumed that these labeled perikarya are those of A10 DA neurons.

\section{Electron microscopic distribution of ${ }^{125} I$-NT-labeled binding sites}

By probability circle analysis, the electron microscopic distribution of silver grains in sections incubated with ${ }^{125}$ I-NT alone (total binding) was found to be significantly different from that in sections incubated with an excess of nonradioactive NT (nonspecific binding), thereby confirming that there had been no artifactual redistribution of bound labeled molecules in the course of histological processing. Both of these distributions were, in 

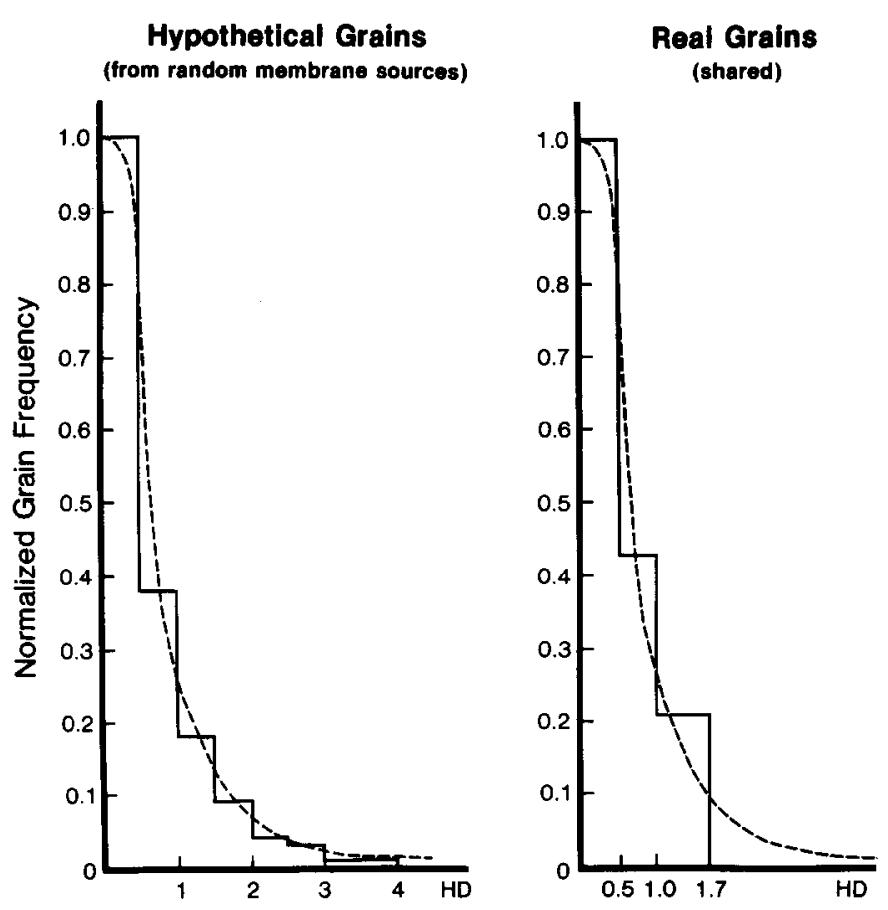

Figure 8. Frequency distribution histogram of shared grains expressed as a function of their distance from the closest plasma membrane (right). This distribution is drawn against the best-fit curve (dotted line) generated from the distribution of hypothetical grains originating from random membrane sources (left) as described in Materials and Methods. Distances on the abscissa are expressed in HD units. Frequencies in ordinate were normalized by setting the grain count in the first column $(0-0.5 \mathrm{HD})$ at unity and adjusting the values in the other columns proportionally. $\chi^{2}$ analysis revealed no statistically significant difference between the 2 distributions $(p \leqq 0.001)$.

turn, significantly different from that of randomly generated hypothetical grains, consistent with the selectivity patterns observed at the light microscopic level.

An important proportion $(\simeq 35 \%)$ of specific grains overlaid single neuronal or glial structures. Most of these clearly originated from intracellular radioactive sources, as less than $10 \%$ of the grains arising from random membrane-bound sources could be expected to end up as "exclusive." In keeping with light microscopic observations, a large number of these exclusive grains were observed over neuronal perikarya and large dendritic shafts. Their frequent association with profiles of rough endoplasmic reticulum or Golgi apparatus suggested that some of the corresponding binding sites may represent receptors undergoing synthesis and glycosylation.

Almost $20 \%$ of exclusive grains overlaid glial profiles, $2 / 3$ of which corresponded to myelin lamellae. Specific binding sites and/or cyclase-linked high-affinity receptor systems for a number of neuropeptides have previously been demonstrated on astrocytes (for review, see Murphy and Pearce, 1987) but never on oligodendroglia. However, both M1 and M2 muscarinic receptor subtypes have been measured in myelin purified from rat brain stem (Larocca et al., 1987). Interestingly, these receptors have been proposed to be involved in the regulation of phosphoinositide metabolism (Larocca et al., 1987), a system to which NT was shown to be linked in rat brain slices (Goedert et al., 1984) and neuroblastoma N1E115 cells (Amar et al., 1987).
Table 3. Radioautographic distribution of nonspecifically bound ${ }^{125} \mathrm{I}-\mathrm{NT}$ molecules in the ventral tegmental area

\begin{tabular}{lrrl} 
& Real grains & \multicolumn{1}{l}{$\begin{array}{l}\text { Hypothetical } \\
\text { grains }^{b}\end{array}$} & Real/Hyp \\
\hline Exclusive & & & \\
Somata & $7.6 \pm 2.0$ & $8.0 \pm 1.6$ & 1.0 \\
Dendrites & $7.6 \pm 0.9$ & $15.4 \pm 1.1$ & 0.5 \\
Axon terminals & $6.3 \pm 1.6$ & $1.1 \pm 0.7$ & 0.6 \\
Myelinated axons & $5.0 \pm 2.4$ & $9.3 \pm 3.5$ & 0.5 \\
Glia & $8.1 \pm 3.3$ & $5.4 \pm 1.0$ & 1.5 \\
Blood vessels & $3.0 \pm 0.3$ & $0.9 \pm 0.2$ & 3.3 \\
Shared & & & \\
Terminal/terminal & $0.4 \pm 0.3$ & $2.1 \pm 1.4$ & 0.2 \\
Terminal/dendrite & $8.1 \pm 4.9$ & $8.4 \pm 1.3$ & 1.0 \\
Terminal/axon & $0.0 \pm 0.0$ & $3.0 \pm 0.4$ & 0.0 \\
Terminal/soma & $0.0 \pm 0.0$ & $0.4 \pm 0.1$ & 0.0 \\
Terminal/glia & $1.2 \pm 0.7$ & $2.3 \pm 0.6$ & 0.5 \\
Dendrite/dendrite & $0.2 \pm 0.1$ & $0.6 \pm 0.3$ & 0.3 \\
Dendrite/axon & $0.0 \pm 0.0$ & $3.9 \pm 0.8$ & 0.0 \\
Dendrite/glia & $5.4 \pm 1.8$ & $2.8 \pm 0.4$ & 1.9 \\
Axon/axon & $0.0 \pm 0.0$ & $4.8 \pm 1.2$ & 0.0 \\
Axon/glia & $8.2 \pm 4.8$ & $2.8 \pm 0.7$ & 3.0 \\
Glia/soma & $0.0 \pm 0.0$ & $0.3 \pm 0.1$ & 0.0 \\
Glia/myelinated axon & $11.2 \pm 3.2$ & $10.4 \pm 2.2$ & 1.1 \\
\hline
\end{tabular}

"Unmyelinated axons referred to as axons.

' Expressed as a percentage of total \pm SEM. Distribution of real grains significantly different from that of hypothetical (Hyp) grains at $p<0.001$.

Finally, a small but significant proportion of cxclusivc grains was found inside axon terminals and cross-sectioned myelinated axons. Such intra-axonal binding sites presumably correspond to receptors in transit either to or from the terminal membrane. Studies on the vagus nerve have indicated that NT binding sites can travel in both antero- and retrograde directions in certain myelinated tracts (Kessler and Beaudet, 1989). Moreover, transport of NT binding sites within DA projections to the neostriatum would be in keeping with the decrease in NT binding reported in the caudate nucleus following cytotoxic destruction of DA neurons in the VTA (Quirion, 1983; Quirion et al., 1985; Hervé et al., 1986).

Most of the silver grains detected over the neuropil were "shared," i.e., overlaid more than one cellular profile. When analyzed as a function of their distance from the closest plasma membrane (line source analysis), the distribution of these shared grains was found to be identical to that of hypothetical grains originating from randomly distributed membrane-associated radioactive sources. We concluded from this observation that shared grains detected in our material had mainly arisen from membrane-bound radioactive sources, and that their distribution could therefore be surmised to give an accurate reflection of the relative repartition of membrane associated NT receptors.

Approximately $16 \%$ of shared grains were found over ter$\mathrm{minal} /$ dendrite and terminal/soma interfaces. Although limitations in the resolution of the technique precluded direct attribution of the labeled receptors to either one of the apposed plasma membranes, several lines of evidence favored an association with the membranes of the somas or dendrites themselves rather than with those of the adjoining axon terminals. These include (1) the presence, in light microscopic radioautograms, of silver grains aligned along the contour of certain 
perikarya and dendrites; (2) the occurrence, at the electron microscopic level, of somatic and dendritic profiles labeled at several loci along their plasma membrane; and (3) the fact that all shared compartments comprising dendritic or somatic membranes, associated or not with axon terminals, showed a high labcling index. This last point further implied that receptors linked to the plasma membranes of perikarya or dendrites were not exclusively present, or even concentrated, opposite abutting axon terminals but rather that they were more or less evenly distributed along dendritic and somatic plasma membranes of ventral tegmental neurons. Given the experimental evidence for an association of these receptors with DA cells (see above), they can be assumed to subserve the aforementioned local regulatory effects of NT on mesocortical, mesolimbic, and/or mesostriatal DA cells. Some might even correspond to autoreceptors in those cells in which DA has been shown to coexist with endogenous NT (Hökfelt et al., 1984).

Almost $6 \%$ of shared grains fell over tissue compartments that involved one or several unmyelinated axons. These axons usually ran in tight bundles, which presumably explains the large number of grains associated with axon/axon interfaces. Because of the exceedingly small diameter of the labeled axons $(\simeq 0.2$ $\mu \mathrm{m})$, it could not be determined whether binding sites associated with them were intracellular or membrane bound. As in myelinated axons, these binding sites might represent intracellular receptors undergoing axonal transport. Alternatively, they might correspond to membrane-bound axonal receptors serving as a substrate for presynaptic actions of NT. The fact that relatively high numbers of labeled receptors were found at the level of terminal/axon and terminal/terminal interfaces, i.e., close to putative sites of endogenous NT release, would be in keeping with the latter interpretation.

The high proportion of shared grains found over compartments involving glial processes, together with the high proportion of exclusive grains seen over glial cells, supports the view that part of the labeled NT receptors might be associated with glial membranes. The majority of glia-associated shared grains, however, was found at the interface between myelinated axons and their myelin sheaths, implying that they could have been associated with axonal as well as with glial plasma membranes.

An important finding of the present study is that specifically labeled NT binding sites were only infrequently associated with synaptic junctions. Other types of neurotransmitter receptors, namely, mu opioid receptors in neostriatum (Hamel and Beaudet, 1987) and locus cocrulcus (E. Moysc and A. Bcaudct, unpublished observations), $\beta$-adrenergic receptors in cerebral cortex (Aoki et al., 1987), and benzodiazepine binding sites in the substantia nigra (Richards et al., 1987, 1988) were similarly found to be only occasionally associated with synaptic contacts. In contrast, receptors for glycine (Triller et al., 1985) or $\alpha$-bungarotoxin (Hunt and Schmidt, 1978; Kuhar et al., 1981; Miller et al., 1987) appear to be much more frequently linked to synaptic differentiations. The possibility that in the present study the incubation procedure had had a deleterious effect on some of the labeled synaptic specializations and that the proportion of synaptic NT receptors is actually higher than that estimated, cannot be excluded. The fact remains, however, that a significant fraction of membrane bound binding sites was not even at close range from axon terminals and could therefore hardly have been associated with a synapse to start with.

A recent electron microscopic double-labeling study has demonstrated that NT immunoreactive axon terminals directly abut, but only infrequently establish differentiated synaptic contacts with, TH-immunoreactive perikarya and dendrites in the rat VTA (Woulfe and Beaudet, 1989). The question therefore arises as to whether all NT binding sites, or only those associated with or facing these axon terminals, correspond to functional receptors. Although further experimental work is obviously needed to settle this issue, the fact that NT is colocalized with DA within the perikaryon and dendrites of certain VTA neurons (Hökfelt et al., 1984) and hence might, like DA (Nieoullon et al., 1977; Tagerud and Cuello, 1979), be released from neuronal elements distinct from axon terminals suggests that the binding sites found here to be widely dispersed along the plasma membrane of presumptive DA cells may serve as a substrate for a fairly widespread, paracrine type of action of the peptide in the VTA.

\section{References}

Amar, S., P. Kitabgi, and J.-P. Vincent (1987) Stimulation of inositol phosphate production by neurotensin in neuroblastoma N1E1 15 cells: Implication of GTP-binding proteins and relationship with the cyclic GMP response. J. Neurochem. 49: 999-1006.

Andrade, R., and K. Aghajanian (1981) Neurotensin selectively activates dopaminergic neurons in the substantia nigra. Soc. Neurosci. Abstr. 7: 573.

Aoki, C., T. H. Joh, and V. M. Pickel (1987) Ultrastructural localization of $\beta$-adrenergic receptor-like immunoreactivity in the cortex and neostriatum of rat brain. Brain Res. 437: 264-282.

Bischoff, S., M. Heinrich, E. Kung, M. Pozza, M. Schaub, K. Stocklin, and A. Vassont (1987) The neurotensin (NT) analogue xenopsin also excites dopamine neurons and induces hypothermia in rats. Soc. Neurosci. Abstr. 13: 1309.

Blackett, N. M., and D. M. Parry (1977) A simplified method of "hypothetical grain" analysis of electron microscope autoradiographs. J. Histochem. Cytochem. 25: 206-214.

Cador, M., A. E. Kelley, M. LeMoal, and L. Stinus (1985) Behavioral analysis of the effect of neurotensin injected into the ventral mesencephalon on investigatory and spontaneous motor behavior in the rat. Psychopharmacology 85: 37-46.

Carraway, R., and S. E. Leeman (1973) The isolation of a new hypotensive peptide, neurotensin from bovine hypothalami. J. Biol. Chcm. 248: 6854-6861.

Carraway, R., and S. E. Leeman (1976) Characterization of radioimmunoassayable neurotensin in the rat. Its distribution in the central nervous system, small intestine and stomach. J. Biol. Chem. 251: 7045-7052.

Cooper, P. E, M. H. Fernstrom, O. P. Rorstad, S. E. Leeman, and J. B. Martin (1981) The regional distribution of somatostatin, substance $\mathrm{P}$ and neurotensin in human brain. Brain Res. 218: 219-232.

Emson, P. C., M. Goedert, P. Horsfield, F. Rioux, and S. St. Pierre (1982) The regional distribution and chromatographic characterization of neurotensin-like immunoreactivity in the central nervous system. J. Neurochem. 38: 992-999.

Emson, P. C., M. Goedert, and P. W. Mantyh (1985) Neurotensincontaining neurons. In Handbook of Chemical Neuroanatomy, Vol. 4, GABA and Neuropeptides in the CNS, Part I, A. Bjorklund and T. Hökfelt, eds., pp. 355-405, Elsevier, Amsterdam.

Goedert, M., R. D. Pinnock, C. P. Downes, P. W. Mantyh, and P. C. Emson (1984) Neurotensin stimulates inositol phospholipid hydrolysis in rat brain slices. Brain Res. 323: 193-197.

Hamel, E., and A. Beaudet (1984) Localization of opioid binding sites in rat brain by electron microscopic radioautography. J. Elect. Microsc. Techn. 1: 317-328.

Hamel, E., and A. Beaudet (1987) Opioid receptors in rat neostriatum: Radioautographic distribution at the electron microscopic level. Brain Res. 401: 239-257.

Hervé, D., J. P. Tassin, J. M. Studler, C. Dana, P. Kitabgi, J. P. Vincent, J. Glowinski, and W. Rostène (1986) Dopaminergic control of ${ }^{125} \mathrm{I}-$ labeled neurotensin binding site density in corticolimbic structures of the rat brain. Proc. Natl. Acad. Sci. USA 83: 6203-6207.

Hökfelt, T., B. J. Everitt, E. Theodorssen-Norheim, and M. Goldstein (1984) Occurrence of neurotensin-like immunoreactivity in subpopulations of hypothalamic, mesencephalic and medullary catecholamine neurons. J. Comp. Neurol. 222: 543-559. 
Hunt, S. P., and J. Schmidt (1978) The electron microscopic autoradiographic localization of $\alpha$-bungarotoxin binding sites within the central nervous system of the rat. Brain Res. 142: 152-159.

Jennes, L., W. E. Stumpf, and P. W. Kalivas (1982) Neurotensin: Topographical distribution in rat brain by immunohistochemistry. $\mathrm{J}$. Comp. Neurol. 210: 211-224.

Kalivas, P. W. (1984) Neurotensin in the ventromedial mesencephalon of the rat: Anatomical and functional considerations. J. Comp. Neurol. 226: 495-507.

Kalivas, P. W. (1985) Interaction between neuropeptides and dopamine neurons in the ventromedial mesencephalon. Neurosci. Behavior. Rev. 9: 573-587.

Kalivas, P. W., C. B. Nemcroff, and A. J. Prange, Jr. (1981) Increases in spontaneous motor activity following infusion of neurotensin into the ventral tegmental area. Brain Res. 229: 525-529.

Kalivas, P. W., L. Jennes, C. B. Nemeroff, and A. J. Prange (1982) Neurotensin: Topographical distribution of brain sites involved in hypothermia and antinociception. J. Comp. Neurol. 210: 225-238.

Kalivas, P. W., S. K. Burgess, C. B. Nemeroff, and A. J. Prange, Jr. (1983) Behavioral and neurochemical effects of neurotensin microinjection into the ventral tegmental area. Neuroscience 8: 495-505.

Kalivas, P. W., C. B. Nemeroff, J. S. Miller, and A. J. Prange, Jr. (1985) Neurotensin hypothermia: Involvement of the mesolimbic dopamine system. Brain Res. 326: 219-227.

Kessler, J. P., and A. Beaudet (1989) Association of neurotensin binding sites with sensory and visceromotor components of the vagus nerve. J. Neurosci. 9: 466-472.

Kitabgi, P., R. E. Carraway, J. Van Rietschoten, C. Granier, J. L. Morgat, A. Menez, S. E. Leeman, and P. Freychet (1977) Neurotensin: Specific binding to synaptic membranes from rat brain. Proc. Natl. Acad. Sci. USA 74: 1846-1850.

Kitabgi, P., F. Checler, J. Mazella, and J. P. Vincent (1985) Pharmacology and biochemistry of neurotensin receptors. Rev. Clin. Bas. Pharmacol. 5: 397-486.

Kitabgi, P., W. Rostène, M. Dussaillant, A. Schotte, P. M. Laduron, and J. P. Vincent (1987) Two populations of neurotensin binding sites in murine brain: Discrimination by the antihistamine levocabastine reveals markedly different radioautographic distribution. Eur. J. Pharmacol. 140: 285-293.

Kobayashi, R. M., M. R. Brown, and W. Vole (1977) Regional distribution of neurotensin and somatostatin in rat brain. Brain Res. 126: 584-588.

Kuhar, M. J., M. Taylor, J. K. Wamsley, E. C. Hulme, and N. J. M. Birdsall (1981) Muscarinic cholinergic receptor localization in brain by electron microscopic autoradiography. Brain Res. 216: 1-9.

Larocca, J. N., R. W. Ledeen, B. Dvorkin, and M. H. Makman (1987) Muscarinic receptor binding and muscarinic receptor-mediated inhibition of adenylate cyclase in rat brain myelin. J. Neurosci. 7: 38693876

Manberg, P. J., W. W. Youngblood, C. B. Nemeroff, M. Rassor, L. L. Iversen, A. J. Prange, Jr., and J. S. Kizer (1982) Regional distribution of neurotensin in human brain. J. Neurochem. 38: 1777-1780.

Mazella, J., C. Poustis, C. Labbé, F. Checler, P. Kitabgi, C. Granier, J. Van Rietschoten, and J. P. Vincent (1983) Monoiodo-Trp ${ }^{11}$ neurotensin, a highly radioactive ligand of ncurotensin receptors. Prcparation, biological activity and binding properties to rat brain synaptic membranes. J. Biol. Chem. 258: 3476-3481.

Miller, M. M., R. B. Billiar, and A. Beaudet (1987) Ultrastructural distribution of alpha-bungarotoxin binding sites in the suprachiasmatic nucleus of the rat hypothalamus. Cell Tissue Res. 250: 13-20.

Moyse, E., W. Rostène, M. Vial, K. Leonard, J. Mazella, P. Kitabgi, J.

P. Vincent, and A. Beaudet (1987) Distribution of neurotensin binding sites in rat brain: A light microscopic radioautographic study using monoiodo $\left(\mathrm{Tyr}^{3}\right)$-neurotensin. Neuroscience 22: 525-536.

Murphy, S., and B. Pearce (1987) Functional receptors for neurotransmitters on astroglial cells. Neuroscience 22: 381-394.

Myers, R. D., and T. F. Lee (1983) In vivo release of dopamine during perfusion of neurotensin in substantia nigra of the unrestrained rat. Peptides 4: 955-961.

Nieoullon, A., A. Cheramy, and J. Glowinski (1977) Release of dopamine in vivo from cat substantia nigra. Nature 266: 357-377.

Palacios, J. M., and M. J. Kuhar (1981) Neurotensin receptors are found on dopamine-containing neurons in rat midbrain: An autoradiographic study. Nature 294: 587-589.

Paxinos, G., and C. Watson (1986) The Rat Brain in Stereotaxic Coordinates. Academic, Sydney.
Phillipson, O. T. (1979) The cytoarchitecture of the interfascicular nucleus and ventral tegmental area of Tsai in the rat. J. Comp. Neurol. 187: 85-98

Pinnock, R. D. (1985) Neurotensin depolarizes substantia nigra dopamine neurones. Brain Res. 338: 151-154.

Quirion, R. (1983) Interaction between neurotensin and dopamine in the brain: An overview. Peptides 4: 609-615.

Quirion, R., P. Gaudreau, S. St. Pierre, F. Rioux, and C. B. Pert (1982) Autoradiographic distribution of ${ }^{3} \mathrm{H}$-neurotensin receptors in rat brain: Visualization by tritium-sensitive film. Peptides 3: 757-763.

Quirion, R., C. C. Chiueh, H. D. Everist, and A. Pert (1985) Comparative localization of neurotensin receptors on nigrostriatal and mesolimbic dopamincrgic tcrminals. Brain Res. 327: 385-389.

Richards, J. G., P. Schoch, P. Haring, B. Takacs, and H. Mohler (1987)

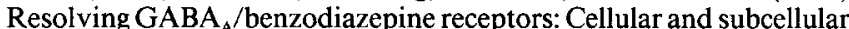
localization in the CNS with monoclonal antibodies. J. Neurosci. 7 : $1866-1886$

Richards, J. G., R. Glinz, P. Schoch, and H. Mohler (1988) New trends in mapping benzodiazepine receptors. Adv. Biochem. Psychopharmacol. 45: 27-46.

Sadoul, J. L., J. Mazella, S. Amar, P. Kitabgi, and J. P. Vincent (1984) Preparation of neurotensin selectively iodinated on the tyrosine 3 residue. Biological activity and binding properties on mammalian neurotensin receptors. Biochem. Biophys. Res. Commun. 120:812819

Salpeter, M. M., F. A. McHenry, and E. E. Salpeter (1978) Resolution in electron microscope autoradiography IV. Application to analysis of autoradiographs. J. Cell Biol. 76: 127-149.

Schotte, A., J. E. Leysen, and P. M. Laduron (1986) Evidence for a displaceable nonspecific ${ }^{3} \mathrm{H}$-neurotensin binding site in rat brain. Naunyn-Schmiedeberg's Arch. Pharmacol. 333: 400-405.

Shi, W. X., and B. S. Bunney (1987) Neurotensin selectively attenuates dopamine inhibition of midbrain dopaminergic neurons. Soc. Neurosci. Abstr. 13: 934

Swanson, L. W. (1982) The projections of ventral tegmental area and adjacent regions: A combined fluorescent retrograde tracer and immunofluorescence study in the rat. Brain Res. Bull. 9: 321-353.

Szigethy, E., and A. Beaudet (1989) Correspondence between high affinity ${ }^{125}$ I-neurotensin binding sites and dopaminergic neurons in the rat substantia nigra and ventral tegmental area: A combined radioautographic and immunohistochemical light microscopic study. J. Comp. Neurol. 279: 128-137.

Tagerud, S. E. O., and A. C. Cuello (1979) Dopamine release from the rat substantia nigra in vitro. Effect of raphe lesions and veratridine stimulation. Neuroscience 4: 2021-2029.

Triller, A., F. Cluzeaud, F. Pfeiffer, H. Betz, and H. Korn (1985) Distribution of glycine receptors at central synapses. An immunoelectron microscopy study. J. Cell Biol. 101: 683-688.

Uhl, G. R. (1982) Distribution of neurotensin and its receptors in the central nervous system. Ann. NY Acad. Sci. 400: 132-149.

Uhl, G. R., and S. H. Snyder (1976) Regional and subcellular distributions of brain neurotensin. Life Sci. 19:1827-1832.

Uhl, G. R., J. P. Bennett, and S. H. Snyder (1977a) Neurotensin: A central nervous system peptide; apparent receptor binding in brain membranes. Brain Res. 130: 299-313.

Uhl, G. R., M. J. Kuhar, and S. H. Snyder (1977b) Neurotensin: Immunohistochemical localization in rat central nervous system. Proc. Natl. Acad. Sci. USA 74: 4059-4063.

Uhl, G. R., R. R. Goodman, and H. S. Solomon (1979) Neurotensincontaining cell bodies, fibers and nerve terminals in the brain stem of the rat: Immunohistochemical mapping. Brain Res. 167: 77-91.

Waters, C. M., S. P. Hunt, P. Jenner, and C. D. Marsden (1987) Localization of neurotensin receptors in the forebrain of the common marmoset and the effects of treatment with the neurotoxin 1-methyl4-phenyl-1,2,3,6-tetrahydropyridine. Brain Res. 412: 244-253.

Williams, M. A. (1969) The assessment of electron microscopic autoradiography. In Advances in Optical and Electron Microscopy, Vol. 3, R. Barer and V. E. Cosslett, eds., pp. 219-272, Academic, London.

Woulfe, J., and A. Beaudet (1989) Immunocytochemical evidence for direct connections between neurotensin-containing axons and dopaminergic neurons in the rat ventral midbrain tegmentum. Brain Res. (in press)

Young, W. S., III, and M. J. Kuhar (1981) Neurotensin receptor localization by light microscopic autoradiography in rat brain. Brain Res. 206: 273-285. 